\title{
Ecstasy-Journey from Consumption to Death
}

\author{
Khushbukhat Khan ${ }^{1 *}$ and Amna Khan ${ }^{2}$ \\ ${ }^{1}$ Center for Applied Molecular Biology, University of the Punjab, Pakistan \\ ${ }^{2}$ Department of Environmental Sciences, International Islamic University, Pakistan
}

*Corresponding author: Khushbukhat Khan, Center for Applied Molecular Biology, 87-West Canal Bank Road, University of the Punjab, Lahore-53700, Pakistan

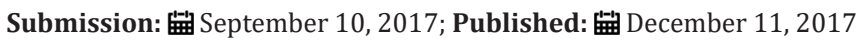

\begin{abstract}
Ecstasy is an illicit compound, use of which is very famous amongst ravers and dance clubbers. It stimulates the over-release of serotonin and other neurotransmitters which psycho-physiologically cause thermal stress, elevated breathing and heartbeat, sharpened visio-audio senses and high blood pressure. User experiences the euphoric, light-minded and optimistic feelings which are exaggerated under loud, crowded and physically wearing environment. Although these feelings are short term and after frequent consumption, wondrous, care-free sensations are superseded by depression, pessimism, sleeplessness and loss of appetite. Current review describes the molecular reasons behind the effects ecstasy poses on naïve users and highlights how addiction for this drug begins and if not controlled how it eventually brings the demise of its users.
\end{abstract}

\section{Introduction}

3,4-methylenedioxymethamphetamine (MDMA) which is commonly known as "ecstasy", is an amphetamine derived illicit compound which stimulates the release of serotonin and other neuro-hormones like cortisol, oxytocin and prolactin [1]. It is highly consumed by youngsters after cannabis. Its peak consumption was reported between early and mid-2000s [2]. But most recently, the use of its highly purified, crystalline prepared form has brought up some serious concerns [1].

Around three decades ago, it was consumed as a recreational drug. Since that time, ecstasy is widely used by youngsters in dance clubs and raves. Initially, college or high school students walking in groups and holding hands or laughing or singing together were recognized as the potential candidates and approached by researchers for MDMA related surveys [2]. MDMA is preferentially used among the youngsters because of its peculiar characteristics like mild hallucination, increased sociability, heightened perception of colour and sound and feeling of empathy [3]. Contrarily, its frequent use or high doses leads to dose dependency which is associated with depressive symptoms, increased anxiety and persistent deficits in cognition [4]. So, the purpose of the current literature is to shed light on the potential mechanism behind imposing its effects and bring into spotlight factors that could lead to its addiction.

\section{Different Routes of MDMA Consumption}

According to global drug survey, the pleasure and risk of any drug is directly linked to the method it is administered by the user. Globally, MDMA is administered either orally in the form of capsule or is inhaled accompanied by physical exertion (e.g. dancing). Around 90\% MDMA users consume it via oral route (among which $48.9 \%$ swallow a capsule, $15.3 \%$ bomb it, $15.1 \%$ use it as dab powder and $9.7 \%$ drink it by dissolving it in any liquid) and $10 \%$ of its users snort it (GDS, 2017).

Ecstasy is easily absorbed from intestinal tract and within 2 hours of its oral consumption, it reaches at its peak plasma concentration. While its administration through nasal route brings about the quicker effect as finely ground drug easily gets absorbed in the porous nasal mucus lining and directly reaches bloodstream. That's why its users are more attracted to snorting because of its rapid onset. The duration of MDMA effect and the duration of its onset after administration are indirectly proportional to each other. Due to quicker drug response, the duration of its effect is shorter which leads to frequent redoes and increases the risk of MDMA resistance. Moreover, rapid increase in its blood concentration puts the user at elevated risk of anxiety, palpitation and perspiration $[5,6]$.

\section{Symptoms and Lethal Effects of MDMA}

MDMA has a potential of showing various psychological and adverse effects along with immune dysfunctioning. The diverse psychological and adverse effects are caused by plasma-MDMA induced elevated secretion levels of cortisol, prolactin, ACTH, dehydroepiandrosterone (DHEA), and antidiuretic hormone (ADH, vasopressin). As the plasma concentration of MDMA changes, it induces various immune dysfunctionalities. These might include CD4 T-helper lymphocytes decreased circulation, increase in NK cells and impaired lymphocyte mitogen-induced proliferation [7]. 
These effects can be categorized into: acute, short-term and chronic effects.

Short-term effects are those that last 24 hours after drug consumption. Depressed mood, fatigue, insomnia, dry mouth, heavy legs, loss of appetite, drowsiness, lack of energy, weakness, muscular tension, lack of concentration and head ache are the short term effects of ecstasy. Late short-term effects of ecstasy include anxiety, drowsiness, lack of energy, fatigue, and muscular tension which last for about 7 days $[3,4]$.

Frequently reported acute side effects reported in the users are lack of appetite, jaw clenching, dry mouth, thirst and restlessness. Some other reported effects include palpitations, impaired balance, sensitivity to cold, drowsiness and insomnia. Muscular tension, anxiety, trismus, nystagmus and tremor are also found to be occurring in frequent users. MDMA also induces panic attacks, delirium and psychotic episodes which are resolved immediately after ceased drug activity $[8,9]$.

Chronic effects of MDMA can be described as mild, moderate or severe. Nausea, vomiting, mydriasis, dry mouth, sweating, restlessness, tremor, hyper-reflexia, irritability, pallor, bruxism, trismus and palpitations are its mild effects. While moderate effects are hyperactivity, aggression, panic attacks, psychosis, muscle tension, tachycardia and increase in body temperature. Severe intoxication leads tohypotension, hyperthermia, seizures, delirium, renal failure and coma.Heat stroke and hyponatremia are another severe complication linked with ecstasy toxicity which ultimately leads to renal failure and hepatic necrosis, respectively $[10,11]$.

\section{Mechanism of Action}

The intensity and time of MDMA effect is largely dependent upon its route of consumption but through whatever route it is consumed it eventually finds its way to liver and there cytochrome P450 (CYP) CYP2D6, 1A2, 2B6, and 3A4 0-demethylenate it and forms 3,4-dihydroxymethamphetamine (HHMA) . If its pharmacokinetics adopt minor pathway, then it is $\mathrm{N}$-demethylenated by the actions of CYP2B6, 1A2, and 2D6 and forms 3,4-methylenedioxyamphetamine (MDA). But before it is metabolized, it binds with CYP2D6 and inhibits its function and accumulates in plasma [12,13]. So, this plasma-MDMA actually interacts with serotonin reuptake transporters (SERT) and triggers the release of serotonin (5-HT) [14]. The elevated level of serotonin leads to serotonin syndrome which along with influential environment (in most cases raves which includes loud music, light shows and are overcrowded) leads to mental confusion, hyperactivity, trismus and hyperthermia [15]. All this in psychophysiology term, causes faster breathing, tachycardia and high blood pressure in ecstasy user [16]. Moreover, MDMA induces the release of $80 \%$ of available serotonin in synaptic cleft [17] which along with reduction in left amygdale activity [18], brings about the initiation of dopamine and NO signaling pathway take a recreational user in a euphoric condition [19]. In this condition, user feels stress free, relax, light minded and loss all judgments for risks.
Meanwhile rest of the CYP enzymes act on MDMA and convert it into its metabolites. Around $10 \%$ of MDMA is converted into MDA [20] which is an agonist for 5-HT receptor and is a potent monoamine releaser [21]. Like MDMA, it is also accumulate in plasma. PlasmaMDA then induces the over-production of cortisol [22] which leads to hyperthermia [14]. This thermal stress makes user feel hot along with pronounced perspiration and dehydration [23]. Some MDMA users then drink water in excessive amount which dilutes blood sodium electrolytes and bring about hyponatraemia [24].

This bust of energy, light-mindedness and joyous sensation feels good initially. But after frequent encounters with MDMA, the levels of serotonin and DA remain stable $[25,26]$. This creates the bodily urge to increase its dose and the phenomenon for addiction begins. NO which is a free radical gas plays very crucial role in addictive behavior. It acts as secondary messenger in central nerves system (CNS) and is produced by NO synthase from L-arginie [25]. The exact mechanism of how MDMA induces its production is still obscure but blocking NO signaling pathway is proven effective in relapse from MDMA abuse [19].

Once addiction for MDMA begins, the user either goes through frequent low dose encounters or sudden exposure to heavy a dose which eventually leads to neural injury at cellular level. Serotonin toxicity is common phenomenon observed [27]. First, its exposure induces the production of reactive oxygen species (ROS) in mitochondria and then initiates caspase dependent apoptosis pathway [28]. Further, MDMA also disrupts the homeostasis of $\mathrm{Ca}^{2+}$ ions by activating calpains and intensify mitochondrial fragmentation [29]. The fragmentation of mitochondria causes accumulation of phagocytes and leads to neurotoxicity [27]. It also induces the expression of Atg5 autophagy gene [30]. This injury consequently results into neuron depletion and chronic tolerance to MDMA. At this stage, all the pleasurable and light-minded sensations first experienced by user are replaced by episodes of depression, insomnia, reduced appetite and adverse health conditions [31,32].

If still the user does not stop and keeps on ingesting heavy doses of ecstasy, then as it activates sympathetic autonomic nervous system, so, user suffers from fever, vasoconstriction and organ failure accompanied by cardiac failure. Later, sufferer also suffers from barotraumas [33].

\section{MDMA to Death}

MDMA or ecstasy is a ring substituted amphetamine which induces the euphoric feelings. Its half life is of 7 hours and reaches its peak levels after 1.5 to 2 hours of consumption. If its concentration elevates to 0.5 to $10 \mathrm{mg} / \mathrm{L}$ in blood then it can pose serious toxic effects and in certain conditions can be life threatening [34,35].

A case study reported the death of 39 years old woman who after oral intake of MDMA collapsed and died after 7 days. On ingesting MDMA, she felt discomfort in anterior chest area and went through cardiopulmonary arrest. Her serum samples were taken on admission in hospital and revealed $1.2 \mathrm{mg} / \mathrm{L}$ MDMA 
concentration. Her autopsy results revealed myocytes necrosis along with macrophage inflammatory response and calcification. Liver necrosis, myoglobinuria, bronchopneumonia and neuron degeneration in whole brain is also reported. All these happenings clearly suggests that the demise of this lady was by MDMA intoxication [34].

The use of MDMA is itself very lethal but its consumption with other substances increases the likelihood of death. A recent study reported the death of 19 year old woman who two days prior to her death took MDMA along with alcohol consumption. The death was caused by diabetic ketoacidosis, a condition provoked by combined ingestion of MDMA and alcohol. Her biochemical tests revealed the vitreous glucose concentration of $6.5 \mathrm{mmol} / \mathrm{L}$ and $13.86 \mathrm{mmol} / \mathrm{L}$ b-OH butyrate. Further, microhemorrhages and swelling in her midbrain and corpus callosum is also reported [36].

\section{Therapeutic Role of MDMA}

Recently the abilities of MDMA has been tested to cure posttraumatic stress disorder (PTSD), a psychologically depressive condition associated with psychological fragmentation, diminished sense of self-worth, trust and safety and loss of sense of selfcoherency. In extreme conditions, PTSD sufferers go through severe personality changes including withdrawal, hopelessness, feeling of emptiness, negative self-perception, low-self esteem and disturbed emotions $[37,38]$.

In such patients, MDMA assisted psychotherapy has shown recuperating outcomes. Positive alteration in the personality structure is reported which accounts for reduction in neuroticism and increase in openness to new social experiences and selfexamination. Such changes ultimately lead to decrease in PTSD symptoms and are long-term [39]. Although, the hallucinogenic property of MDMA [3] is proven beneficial to improve depressive symptoms, still, more clinic experimentation is requisite to further understand its curative properties.

\section{Conclusion}

MDMA is a popular choice of recreational drug amongst youngsters and is usually used in raves and dance club. Naïve users enjoy its euphoric properties under loud and physically extorting environment. At molecular level, such users experience bust of serotonin and electrolyte imbalance which in long run leads to depression, anti-social behavior, organ failure and cardiac failure. So, ecstasy is actually a method of slow-suicide adopted by young generations which after 5-10 years of frequent use irreversibly damage neural system of users. Although anti-narcotic agencies are trying to control its trafficking worldwide and awareness programs are also being run. Still, there is a strong urge to monitor its use in colleges and universities. University administrations should periodically conduct seminars and workshops to aware youngsters and their parents about the dark side of drug use and should also spread knowledge on avoiding the impulse for its use. Through the effort of many researchers, today we know most about the mechanism of MDMA addiction and also know potential ways to heal from its addiction. Despite all that, the room for more confirmatory experiments and discovery of novel recovery treatments is still available.

\section{References}

1. Mounteney J, Griffiths P, Sedefov R, Noor A, Vicente J, et al. (2016) The drug situation in Europe: an overview of data available on illicit drugs and new psychoactive substances from European monitoring in 2015. Addiction 111(1): 34-48

2. Degenhardt L, Hall W (2010) The health and psychological effects of ecstasy (MDMA) Use. National Drug and Alcohol Research Centre, University of New South Wales Sydney, Australia.

3. Green AR, Mechan AO, Elliott JM, O'Shea E, Colado MI, et al. (2003) The pharmacology and clinical pharmacology of 3 , 4-methylenedioxymethamphetamine (MDMA, "ecstasy"). Pharmacol Rev 55(3): 463-508.

4. Parrott AC (2013) Human psychobiology of MDMA or 'Ecstasy': an overview of 25 years of empirical research. Hum Psychopharmacol 28(4): 289-307.

5. Winstock AR, Maier LJ, Ferris JA, Barratt MJ (2017) The Global Drug Survey: how online methods and independence offer alternative perspectives on drug use, Lisbon Addictions: $2^{\text {nd }}$ European Conference on Addictive Behaviours and Dependencies.

6. Kalant H (2001) The pharmacology and toxicology of "ecstasy" (MDMA) and related drugs. CMAJ 165(7): 917-928.

7. De la Torre R, Farré M, Roset PN, Pizarro N, Abanades S, et al. (2004) Human pharmacology of MDMA: pharmacokinetics, metabolism, and disposition. Ther Drug Monit 26(2): 137-144.

8. Pacifici R, Zuccaro P, Farré M, Pichini S, Di Carlo S, et al. (2001) Effects of repeated doses of MDMA ("ecstasy") on cell-mediated immune response in humans. Life Sci 69(24): 2931-2941.

9. Pacifici R, Zuccaro P, Farre M, Pichini S, Di Carlo S, et al. (2000) Immunomodulating activity of MDMA. Ann N Y Acad Sci 914(1): 215224.

10. Cole JC, Sumnall HR (2003) Altered states: the clinical effects of Ecstasy. Pharmacol Ther 98(1): 35-58.

11. Camí J, Farré M, Mas M, Roset PN, Poudevida S, et al. (2000) Human pharmacology of 3, 4-methylenedioxymeth-amphetamine ("Ecstasy"): psychomotor performance and subjective effects. J Clin Psychopharmacol 20(4): 455-466.

12. Yang J, Jamei M, Heydari A, Yeo KR, de la Torre R, et al. (2006) Implications of mechanism-based inhibition of CYP2D6 for the pharmacokinetics and toxicity of MDMA. J Psychopharmacol 20(6): 842-849.

13. Shima N, Katagi M, Kamata H, Zaitsu K, Kamata T, et al (2008) Urinary excretion of the main metabolites of 3 , 4-methylenedioxymethamphetamine (MDMA), including the sulfate and glucuronide of 4-hydroxy-3-methoxymethamphetamine (HMMA), in humans and rats. Xenobiotica 38(3): 314-324.

14. Concheiro M, Baumann MH, Scheidweiler KB, Rothman RB, Marrone GF, et al. (2014) Nonlinear pharmacokinetics of $( \pm) 3$ 4-methylenedioxymethamphetamine (MDMA) and its pharmacodynamic consequences in the rat. Drug Metab Dispos 42(1): 119-125.

15. Parrott A (2002) Recreational Ecstasy/MDMA, the serotonin syndrome, and serotonergic neurotoxicity. Pharmacol Biochem Behav 71(4): 837844.

16. Liechti ME, Gamma A, Vollenweider FX (2001) Gender differences in the subjective effects of MDMA. Psychopharmacology (Berl) 154(2): 161168. 
17. Cadet JL, Krasnova IN, Jayanthi S, Lyles J (2007) Neurotoxicity of substituted amphetamines: molecular and cellular mechanisms. Neurotox Res 11(3-4): 183-202.

18. Gamma A, Buck A, Berthold T, Hell D, Vollenweider FX (2000) 3, 4-Methylenedioxymethamphetamine (MDMA) modulates cortical and limbic brain activity as measured by [H2150]-PET in healthy humans. Neuropsychopharmacology 23(4): 388-395.

19. García-Pardo M, Rodríguez-Arias M, Miñarro J, Aguilar M (2017) Role of nitric oxide pathway in the conditioned rewarding effects of MDMA in mice. Behav Brain Res 330: 75-77.

20. de la Torre R, Farré M (2004) Neurotoxicity of MDMA (ecstasy): the limitations of scaling from animals to humans. Trends Pharmacol Sci 25(10): 505-508.

21. Baumann MH, Rothman RB (2009) Neural and cardiac toxicities associated with 3, 4-methylenedioxymethamphetamine (MDMA). Int Rev Neurobiol 88: 257-296.

22. Parrott A (2012) MDMA and temperature: a review of the thermal effects of 'Ecstasy' in humans. Drug Alcohol Depend 121(1-2): 1-9.

23. Parrott AC, Lock J, Conner A, Kissling C, Thome J (2008) Dance clubbing on MDMA and during abstinence from Ecstasy/MDMA: prospective neuroendocrine and psychobiological changes. Neuropsychobiology 57(4): 165-180.

24. Van Dijken GD, Blom RE, Hené RJ, Boer WH (2013) High incidence of mild hyponatraemia in females using ecstasy at a rave party. Nephrol Dial Transplant 28(9): 2277-2283.

25. Liddie S, Balda MA, Itzhak Y (2013) Nitric oxide (NO) signaling as a potential therapeutic modality against psychostimulants. Curr Pharm Des 19(40): 7092-7102.

26. Van Huijstee AN, Mansvelder HD (2014) Glutamatergic synaptic plasticity in the mesocorticolimbic system in addiction. Front Cell Neurosci 8: 466.

27. Mercer LD, Higgins GC, Lau CL, Lawrence AJ, Beart PM (2017) MDMAinduced neurotoxicity of serotonin neurons involves autophagy and rilmenidine is protective against its pathobiology. Neurochem Int 105: 80-90.

28. Jiménez A, Jordà EG, Verdaguer E, Pubill D, Sureda FX, et al. (2004) Neurotoxicity of amphetamine derivatives is mediated by caspase pathway activation in rat cerebellar granule cells. Toxicol Appl Pharmacol 196(2): 223-234.

29. Barbosa DJ, Serrat R, Mirra S, Quevedo M, de Barreda EG, et al. (2014) The mixture of "ecstasy" and its metabolites impairs mitochondrial fusion/fission equilibrium and trafficking in hippocampal neurons, at in vivo relevant concentrations. Toxicol Sci 139(2): 407-420.

30. Chae M, Rhee GS, Jang IS, Kim K, Lee JH, et al. (2009) ATG5 expression induced by MDMA (ecstasy), interferes with neuronal differentiation of neuroblastoma cells. Mol Cells 27(5): 571-575.

31. Greer G, Tolbert R (1986) Subjective reports of the effects of MDMA in a clinical setting. J Psychoactive Drugs 18(4): 319-327.

32. Hammersley R, Ditton J, Smith I, Short E (1999) Patterns of ecstasy use by drug users. British Journal of Criminology 39(4): 625-647.

33. Van den KE, Roosens L, Siozopoulou V, Verbrugghe W, Aerts J, et al. (2017) Airway necrosis and barotrauma after Ecstasy (MDMA) inhalation. Am J Respir Crit Care Med 196(1):105-106.

34. Sano R, Hasuike T, Nakano M, Kominato Y, Itoh H (2009) A fatal case of myocardial damage due to misuse of the "designer drug" MDMA. Leg Med 11(6): 294-297.

35. Eede HV, Montenij LJ, Touw DJ, Norris EM (2012) Rhabdomyolysis in MDMA intoxication: a rapid and underestimated killer "Clean" ecstasy, a safe party drug? The Journal of emergency medicine 42(6): 655-658.

36. Gilbert JD, Byard RW (2017) Fatal diabetic ketoacidosis-A potential complication of MDMA (Ecstasy) Use. J Forensic Sci doi: 10.1111/15564029.13602 .

37. Beltran RO, Llewellyn GM, Silove D (2008) Clinicians' understanding of international statistical classification of diseases and related health problems, $10^{\text {th }}$ Revision diagnostic criteria: F62. 0 enduring personality change after catastrophic experience. Compr Psychiatry 49(6): 593-602.

38. Cloitre M, Stolbach BC, Herman JL, Kolk BVD, Pynoos R, et al. (2009) A developmental approach to complex PTSD: childhood and adult cumulative trauma as predictors of symptom complexity. J Trauma Stress 22(5): 399-408.

39. Wagner MT, Mithoefer MC, Mithoefer AT, MacAulay RK, Jerome L, et al. (2017) Therapeutic effect of increased openness: investigating mechanism of action in MDMA-assisted psychotherapy. J Psychopharmacol 31(8): 967-974. 